\title{
EDITORIAL
}

\section{Matthias Glö̈L}

\section{EDITOR}

Damos la bienvenida a los lectores a este nuevo número de la revista Cuhso, el segundo de este año 2021. También en esta ocasión el número se compone por un dossier temático y por textos pertenecientes a la sección varia. El dossier coordinado por el doctor en arqueología Alberto Pérez está dedicado a profundizar el debate de antiguos y novedosos materialidades y aspectos inmateriales de interés arqueológico que aporten al conocimiento del pasado acerca del territorio históricamente denominado Wallmapu y sus protagonistas.

La parte de temática varia se divide esta vez en Artículos de Investigación, con siete contribuciones, Ensayos y Revisiones Teóricas con cuatro textos y, finalmente, Reseñas que cuenta con dos aportaciones.

La sección de Artículos de Investigación abre con un trabajo colaborativo de Luis Campos Medina, Víctor Suazo Pereda y Andrea Cárdenas Piñero. Quienes analizan la relegación urbana, por parte de habitantes pobres que fueron relocalizados en la ciudad de Villa Alemana, con posterioridad al gran incendio de Valparaíso de 2014 a través de los relatos de los afectados. La investigación se abordó desde cuatro dimensiones: (1) sentimiento de abandono del Estado; (2) estigmatización socio-territorial; (3) modalidades de sociabilidad barrial; (4) merma del capital espacial.

El siguiente trabajo también abarca cuestiones sociales de alto impacto en Chile. Natalie Martin y Jimena Tapia presentan un texto dedicado a las intervenciones realizadas en diez Monumentos Históricos Nacionales (MHN) del casco fundacional de la ciudad de Santiago en el contexto del estallido social de Octubre 2019. Otra temática relativa a lo social se aborda en el artículo de Francisca Ortiz Ruiz, Camila Moyano Dávila y Daniela Moyano Dávila. Las autoras analizan cuatro carreras de académicos de Química, de una universidad chilena, enfocándose en las diferencias entre varones y mujeres en cuanto a que tener un hijo afecta dicha carrera.

Sigue un texto relacionado al ámbito de la economía. Su autor Damir Galaz-Mandakovic Fernández describe y analiza un proceso derivado de la gran minería del cobre y de la generación de energía eléctrica necesaria para desarrollarla en el primer lustro el siglo XXI. Habla de "Necroeconomía” para el caso del petcoke en Tocopilla para visibilizar una de las funciones adversas del capitalismo y sus agentes subalternos en la política, el cual produce una población superflua, la cual ya no es necesario 
"explotar" sino que gestionar: una manera de disponer de estos excedentes de población es exponerlos a todo tipo de peligros y riesgos.

A continuación tenemos la contribución de Daniça Cid y Francisco Araos sobre los Espacios Costeros Marinos para Pueblos Originarios (ECMPOs) que se han transformado en el principal mecanismo para el resguardo de los modos de vida de los pueblos indígenas y promoción de la sustentabilidad marinocostera del sur de Chile. El artículo analiza las contribuciones de los ECMPOs al bienestar humano de las comunidades indígenas.

Vinculado al área de las ciencias políticas se ubica el artículo de Juan Antonio González de Requena Farré. Quien investiga el léxico y doble discurso del conservadurismo político chileno en la primera mitad del siglo XX, basándose en declaraciones políticas de los partidos conservadores chilenos en 1878, 1918, 1932 y 1953.

La sección cierra con el aporte de Carlos Fernando Araya Paz sobre la transparencia algorítmica y la pregunta de si se trata de un problema de tipo normativo o más bien de uno tecnológico.

La sección Ensayos y Revisiones Teóricas comienza con otra contribución del ámbito de la economía. Su autor Miguel Rigoberto Sánchez García establece una relación entre la violencia extrema y la imposición de un modelo de desarrollo capitalista. El análisis conecta la violencia de la dictadura de Pinochet y la represión contemporánea utilizada para facilitar la extracción de madera del territorio tradicional mapuche.

El siguiente texto de Raúl González Meyer y Stefano Micheletti propone una reflexión sobre la re-conceptualización de lo local en un contexto de globalización, y analiza en términos teóricos cuáles son las posibilidades efectivas de que se mantengan, refuercen o desencadenen dinámicas de desarrollo local endógeno, entendido como proceso con alto protagonismo de las sociedades locales y, también, como enfoque alternativo.

Continúa otro aporte desde las ciencias políticas, concretamente del contexto argentino. Su autor Ignacio Andrés Rossi reflexiona sobre la transición democrática en Argentina y el gobierno de Raúl Alfonsín de 1983 a 1985. Pretende analizar cómo, desde 1983 el alfonsinismo se propuso construir dicho programa, sus principales dificultades, el espíritu del mismo y algunas reflexiones en torno a los planes económicos y la reforma del Estado en un contexto de profundos deterioros macroeconómicos.

Finalmente, presentamos una contribución del área de la filosofía, concretamente de la perspectiva del ser en Jean Paul Sartre. La autora resume brevemente un recorrido por la obra sartreana, colocando énfasis en su concepción del Ser a través de dos obras por las que sentimos profundo respeto: El Ser y la Nada (SYN) y Critica a la Razón dialéctica (CRD). Su objetivo en ello es bosquejar su camino intelectual desde un solipsismo excesivo a un ser claramente incrustado en la historia y alejado del ser natural. 
Cerramos el número con dos reseñas bibliográficas. Por una parte, Diego Aniñir Manríquez analiza la obra. Fütra Waria o Capital del Reyno. Imágenes, escrituras e historias mapuche en la gran ciudad 1927-1992, publicada por Enrique Antileo y Claudio Alvarado. Por otra parte, Pablo Betancur nos presenta la obra Antropología Contemporánea: intersecciones, encuentros y reflexiones desde el Sur Sur, editada por Gonzalo Díaz Crovetto. 


\title{
CUHSO
}

Fundada en 1984, la revista CUHSO es una de las publicaciones periódicas más antiguas en ciencias sociales y humanidades del sur de Chile. Con una periodicidad semestral, recibe todo el año trabajos inéditos de las distintas disciplinas de las ciencias sociales y las humanidades especializadas en el estudio y comprensión de la diversidad sociocultural, especialmente de las sociedades latinoamericanas y sus tensiones producto de la herencia colonial, la modernidad y la globalización. En este sentido, la revista valora tanto el rigor como la pluralidad teórica, epistemológica y metodológica de los trabajos.

\author{
EDITOR \\ Matthias Gloël
}

COORDINADORA EDITORIAL

Claudia Campos Letelier

CoRRECTOR DE ESTILO Y DISEÑAdOR

Ediciones Silsag

TRADUCTOR, CORRECTOR LENGUA INGLESA

Aurora Sambolin Santiago

SITIO WEB

cuhso.uct.cl

E-MAIL

cuhso@uct.cl

LICENCIA DE ESTE ARTÍCULO

Creative Commons Atribución Compartir Igual 4.0 Internacional 